\title{
Penggunaan Video Screencast O-Matic Pada Mata Kuliah Aljabar Abstrak
}

\author{
Enny Listiawati \\ STKIP PGRI Bangkalan, Jalan Soekarno Hatta Nomer 52 Bangkalan \\ e-mail: ennylistiawati@stkippgri-bkl.ac.id
}

\begin{abstract}
In the millennial era an innovative and creative learning media is needed by utilizing technology that can improve the quality of student learning in abstract algebra lectures. One of them is by using Screencast O-Matic (SOM) software application. SOM is software that is generally used for making tutorial videos to explain or explain learning material.The purpose of this study was to determine the effectiveness of the use of SOM in abstract algebra learning in terms of student activity and completeness of student learning outcomes. The subjects of this study were the 5th semester students of the 5th semester Mathematics education program at STKIP Bangkalan PGRI who were participating in the Abstract Algebra course. 35 students. This type of research is quantitative descriptive, with the research instruments being the observation sheet of student activities and learning outcomes test questions.

The results of this study are the use of Screencast $O$-matic software media in learning abstract algebra courses said to be effective based on indicators of effectiveness consisting of effective student activities and student learning outcomes completed in a classical manner.
\end{abstract}

Keywords: Screencast O-Matic, Student Activities, Classical completeness

\section{Pendahuluan}

Dalam perkembangan teknologi saat ini berdampak adanya perubahan pada segala aspek kehidupan manusia termasuk juga dalam aspek pendidikan. Pada aspek pendidikan, teknologi memiliki peranan penting karena dengan memanfaatkan kemajuan teknologi maka kegiatan dalam proses pembelajaran dapat lebih berkualitas. Hal ini disebabkan oleh, pendidik dapat melaksanakan kegiatan pembelajaran lebih menarik, variatif, inovatif dan fleksibel. Dengan fasilitas teknologi yang ada, maka proses pembelajaran tidak hanya dilakukan secara konvensional, akan tetapi bisa dengan digabungkan dengan pembelajaran secara daring yang lebih dikenal dengan blended learning. Akan tetapi dalam kenyataannya, masih banyak pendidik dalam hal ini dosen yang masih melakukan kegiatan pembelajaran secara konvensional tanpa memanfaatkan teknologi yang ada.

Hal ini juga terjadi pada proses perkuliahan mata kuliah Aljabar abstrak pada prgram studi pendidikan matematika STKIP PGRI Bangkalan. Selama ini dosen hanya menggunakan metode pembelajaran konvensional tanpa memanfaatkan teknologi. Sumber belajar mahasiswa selama ini hanya menggunakan menggunakan buku atau 
modul baik dalam bentuk softfile maupun hardfile. Dengan menggunakan metode pembelajaan tersebut tidak perhatian mahasiswa pada proses pembelajaran sebab dengan melihat kondisi mahasiswa pada saat ini yang cenderunglebih dekat dengan teknologi, maka mahasiswa tidak begitu tertarik dengan media pembelajaran yang bersifat monoton seperti buku atau alat peraga.

Dengan melihat kondisi tersebut menarik, maka dosen selaku pendidik harus lebih kreatif dan inovatif dalam menyampaikan materi ajar dikelas. Salah satu caranya adalah dengan memanfaatkan teknologi dan sumber belajar agar kegiatan pembelajaran lebih berkualitas dan menarik. Pemanfaatkan media pembelajaran yang inovatif tersebut diharapkan dapat meningkatkan efektivitas dan kualitas pembelajaran pada mata kuliah aljabar abtrak. Hal ini sesuai dengan penelitian yang dilakukan oleh Saputra dan Purnama [1] yang menyatakan bahwa penggunaan media pembelaran interaktif dapat membantu pengguna dalam pembelajaran mandiri. Selain itu tampilan menarik dan fasilitas suara yang ada membuat pengguna lebih tertarik untuk belajar.

Banyak metode dan media yang dapat digunakan untuk meningkatkan kualitas pembelajaran..Salah satu media yang dapat digunakan dalam pembelajaran blended learning adalah penggunaan video pembelajaran dengan menggunakan Software Screencat O-Matic (SOM). Menurut Tim LPPI Unipa Surabaya [2], SOM secara garis besar merupakan software yang pada umumnya digunakan untuk pembuatan video pemaparan atau penjelasan materi pembelajaran. Dengan demikian dosen dapat menjelaskan materi secara rinci dengan memanfaatkan SOM dan dapat disampaikan kepada mahasiswa baik secara langsung maupun secara daring.

Dengan menggunakan media SOM dalam pembelajaran, diharapkan pesan pembelajaran akan lebih sampai kepada mahasiswa. Hal ini sejalan dengan pendapat Latuheru [3] yang menyatakan bahwa media pembelajaran adalah alat bantu untuk menyampaikan pesan dari sumber kepada penerima. Dengan demikian diharapkan mahasiswa akan lebih mengerti dan memahami materi pada perkuliahan aljabar abstrak. Hal ini sejalan dengan pendapat Heinich dalam Arsyad [4] yang menyatakan bahwa media merupakan alat saluran komunikasi. Alat saluran komunikasi antara mahasiswa dan dosen.

Dari uraian latar belakang tersebut, maka peneliti tertarik melakukan penelitian tentang "Penggunaan Software Screencat O-Matic Pada Pembelajaran Mata Kuliah Aljabar Abstrak". Materi yang akan digunakan dalam penelitian ini adalah sifat-sifat Grup. Adapun rumusan masalah dalam penelitian ini adalah bagaimanakah aktivitas dan hasil belajar mahasiswa pada mata kuliah aljabar abstrak dengan menggunakan software Screencast O-Matic?. Adapun tujuan dalam penelitian ini adalah untuk mendeskripsikan aktivitas dan hasil belajar mahasiswa pada mata kuliah aljabar abstrak dengan menggunakan software Screencast O-Matic. Manfaat dari penelitian ini adalah dapat 
memberikan referensi kepada dosen dalam pembelajaran dan referensi teori kepada peneliti lain

\section{Metode Penelitian}

Jenis penelitian ini termasuk penelitian deskriptif kuantitatif karena tujuan penelitian ini adalah untuk mendeskripsikan aktvitas dan hasil belajar mahasiswa pada mata kuliah aljabar abstrak dengan menggunakan Software Screencat O-Matic,adapun teknik analisis data hasil penelitian menggunakan statistik deskriptif. Subjek penelitian ini adalah adalah mahasiswa Program Studi Pendidikan Matematika Semester V STKIP PGRI Bangkalan yang terdiri dari 35 mahasiswa. Penelitian ini dilakukan selama satu bulan yaitu dari bulan November sampai Desember tahun 2018. Instrumen dalam penelitian ini adalah lembar observasi aktivitas mahasiswa dan soal tes hasil belajar mahasiswa.

Instrumen lembar observasi aktivitas mahasiswa digunakan untuk mengetahui aktivitas mahasiswa selama proses pembelajaran berlangsung. Observasi ini dilakukan oleh seorang pengamat selama proses pembelajaran. Instrumen berikutnya adalah soal tes hasil belajar mahasiswa digunakan untuk mengetahui ketuntasan hasil belajar mahasiswa. Soal tes ini berupa soal uraian pada materi sifat-sifat grup yang diberikan kepada mahasiswa diakhir pembelajaran.

\subsection{Teknis analisis data aktivitas mahasiswa}

Data hasil pengamatan aktivitas mahasiswa selama kegiatan pembelajaran dianalisis dengan menggunakan persentase.

Persentase aktivitas mahasiswa $=\frac{\text { frekuensi setiap aspek pengamatan }}{\text { Jumlah frekuensi aspek pengamatan }} \times 100 \%$

Penentuan kriteria keefektifan aktivitas mahasiswa berdasarkan pencapaian waktu ideal yang ditetapkan dalam penyusunan rencana pelaksanaan pembelajaran yang sudah dinyatakan baik (hasil dari revisi validasi) didasarkan pada pencapaian waktu ideal seperti yang ditentukan pada Tabel 1.

Pada analisis ini dilakukan untuk seluruh aktivitas mahasiswa dari 6 (enam) mahasiswa terpilih. Aktivitas mahasiswa di kelas dikatakan efektif jika rata-rata waktu dari semua pertemuan yang digunakan, minimal ada 7 aspek aktivitas mahasiswa berada dalam kriteria batasan efektif yang ditetapkan dan batas toleransi 5\% dari waktu ideal. 
Tabel 1. Kriteria Batas Efektifitas Aktivitas Mahasiswa dalam Pembelajaran

\begin{tabular}{lcc}
\hline \multicolumn{1}{c}{ Aspek Pengamatan Aktivitas Mahasiswa } & \multicolumn{2}{c}{ Persentase Kesesuaian (P) } \\
\cline { 2 - 3 } & Waktu Ideal & Interval Toleransi \\
\hline 1. Mendengarkan/memperhatikan penjelasan dosen & 6,67 & $6,33-7$ \\
\hline $\begin{array}{l}\text { 2. Berkumpul dengan anggota kelompoknya masing- } \\
\text { masing }\end{array}$ & 3,33 & $3,17-3,5$ \\
\hline $\begin{array}{l}\text { 3. Mengamati dan mencermati materi yang disajikan } \\
\text { pada video Screencast O-Matic }\end{array}$ & 13,33 & $12,67-14$ \\
\hline $\begin{array}{l}\text { 4. Mengamati dan mencermati pertanyaan yang terdapat } \\
\text { pada video }\end{array}$ & 6,67 & $6,33-7$ \\
\hline $\begin{array}{l}\text { 5. Menjawab pertanyaan yang terdapat pada video SOM } \\
\text { dan bertanya jika terdapat hal yang kurang di- } \\
\text { mengerti }\end{array}$ & 6,67 & $6,33-7$ \\
\hline 6. Melakukan diskusi dengan kelompok & 16,67 & $15,83-17,5$ \\
\hline $\begin{array}{l}\text { 7. Mendengarkan dan menangapi kelompok yang } \\
\text { mempresentasikam hasil kerjanya di depan kelas }\end{array}$ & 13,33 & $12,67-14$ \\
\hline 8. Melakukan tanya jawab dengan dosen & 6,67 & $6,33-7$ \\
\hline 9. Mencatat dan merangkum materi & 6,67 & $6,33-7$ \\
\hline $\begin{array}{l}\text { 10. Mengerjakan soal Evaluasi } \\
\text { 11. Melakukan kegiatan yang tidak relevan dengan pem- } \\
\text { belajaran }\end{array}$ & 0 & $19-21$ \\
\hline
\end{tabular}

\subsection{Analisis Data Tes Hasil Belajar Mahasiswa}

Tes digunakan untuk memperoleh data hasil belajar mahasiswa, tes diberikan dalam bentuk soal.

Nilai akhir mahasiswa diperoleh dengan rumus sebagai berikut :

$$
\mathrm{NA}=\frac{\text { skor yang diperoleh siswa }}{\text { total skor }} \times 100
$$

dengan NA = Nilai Akhir Tes Hasil Belajar Mahasiswa

Mahasiswa dinyatakan tuntas belajar apabila hasil belajar yang diperoleh mencapai nilai $\geq 70$ sesuai dengan Kriteria Ketuntasan Minimal (KKM) pada mata kuliah Aljabar Abstrak.

Persentase ketuntasan belajar mahasiswa secara klasikal dihitung dengan rumus sebagai berikut :

$$
\mathrm{P}=\frac{\sum \text { siswa yang tuntas belajar }}{\sum \text { siswa seluruhnya }} \times 100 \%
$$

Dengan P = Persentase Ketuntasan Belajar secara Klasikal

Indikator ketuntasan belajar mahasiswa secara klasikal apabila $\geq 80 \%$ dari seluruh mahasiswa dinyatakan tuntas belajar, sesuai dengan yang telah ditetapkan pada mata kuliah Aljabar Abstrak. 


\section{Hasil dan Pembahasan}

\subsection{Data Aktivitas Mahasiswa}

Hasil pengamatan terhadap aktivitas 6 mahasiswa disajikan pada Tabel 2 .

Tabel 2. Rekapitulasi Aktivitas Mahasiswa dalam Pembelajaran

\begin{tabular}{|c|c|c|c|}
\hline No & Aspek Pengamatan Aktivitas Mahasiswa & $\begin{array}{l}\text { Persentase Aktivi- } \\
\text { tas Mahasiswa (\%) }\end{array}$ & $\begin{array}{l}\text { Toleransi Keefek- } \\
\text { tifan }(\%)\end{array}$ \\
\hline 1 & $\begin{array}{l}\text { Mendengarkan/memperhatikan penjelasan } \\
\text { dosen }\end{array}$ & 6,67 & $6,33-7$ \\
\hline 2 & $\begin{array}{l}\text { Berkumpul dengan anggota kelompoknya } \\
\text { masing-masing }\end{array}$ & 6,67 & $3,17-3,5$ \\
\hline 3 & $\begin{array}{l}\text { Mengamati dan mencermati materi yang } \\
\text { disajikan pada video Screencast O-Matic }\end{array}$ & 13,33 & $12,67-14$ \\
\hline 4 & $\begin{array}{l}\text { Mengamati dan mencermati pertanyaan } \\
\text { yang terdapat pada video }\end{array}$ & 6,67 & $6,33-7$ \\
\hline 5 & $\begin{array}{l}\text { Menjawab pertanyaan yang terdapat pada } \\
\text { video SOM dan bertanya jika terdapat hal } \\
\text { yang kurang dimengerti }\end{array}$ & 6,67 & $6,33-7$ \\
\hline 6 & Melakukan diskusi dengan kelompok & 6,67 & $15,83-17,5$ \\
\hline 7 & $\begin{array}{l}\text { Mendengarkan dan menangapi kelompok } \\
\text { yang mempresentasikan hasil kerjanya di } \\
\text { depan kelas }\end{array}$ & 13,33 & $12,67-14$ \\
\hline 8 & Melakukan tanya jawab dengan dosen & 6,67 & $6,33-7$ \\
\hline 9 & Mencatat dan merangkum materi & 13,33 & $6,33-7$ \\
\hline 10 & Mengerjakan soal Evaluasi & 20 & $19-21$ \\
\hline 11 & $\begin{array}{l}\text { Melakukan kegiatan yang tidak relevan } \\
\text { dengan pembelajaran }\end{array}$ & 0 & $0-0$ \\
\hline
\end{tabular}

Berdasarkan Tabel 2, terlihat bahwa ada 8 aspek pengamatan aktivitas mahasiswa berada pada batas toleransi dan 3 aspek pengamatan aktivitas mahasiswa tidak berada pada batas toleransi. Dengan demikian aktivitas mahasiswa pada mata kuliah aljabar abstrak dengan menggunakan Screencast $O$-Matic dikatakan efektif.

\subsection{Data Hasil Belajar Mahasiswa}

Data hasil belajar mahasiswa diperoleh dari hasil tes hasil belajar mahasiswa setelah pembelajaran. Data hasil belajar mahasiswa dapat dilihat pada Tabel 3. 
Tabel 3. Data Hasil Belajar Mahasiswa

\begin{tabular}{cccccc}
\hline Kode & Nilai & Keterangan & Kode & Nilai & Keterangan \\
\hline 1 & 62 & Tdk Tuntas & 19 & 61 & Tdk Tuntas \\
\hline 2 & 60 & Tuntas & 20 & 100 & Tuntas \\
\hline 3 & 61 & Tdk Tuntas & 21 & 62 & Tdk Tuntas \\
\hline 4 & 100 & Tuntas & 22 & 91 & Tuntas \\
\hline 5 & 91 & Tuntas & 23 & 100 & Tuntas \\
\hline 6 & 91 & Tuntas & 24 & 91 & Tuntas \\
\hline 7 & 90 & Tuntas & 25 & 91 & Tuntas \\
\hline 8 & 100 & Tuntas & 26 & 91 & Tuntas \\
\hline 9 & 100 & Tuntas & 27 & 41 & Tdk Tuntas \\
\hline 10 & 81 & Tuntas & 28 & 41 & Tdk Tuntas \\
\hline 11 & 81 & Tuntas & 29 & 61 & Tdk Tuntas \\
\hline 12 & 100 & Tuntas & 30 & 61 & Tdk Tuntas \\
\hline 13 & 90 & Tuntas & 31 & 61 & Tuntas \\
\hline 14 & 91 & Tuntas & 32 & 61 & Tuntas \\
\hline 15 & 91 & Tuntas & 33 & 72 & Tuntas \\
\hline 16 & 100 & Tuntas & 34 & 72 & Tuntas \\
\hline 17 & 32 & Tdk Tuntas & 35 & 91 & Tuntas \\
\hline 18 & 31 & Tdk Tuntas & & \\
\hline
\end{tabular}

Berdasarkan tabel 3 tersebut, kemudian data dirangkum dan dianalisis untuk menentukan persentase ketuntasam klasikal mahasiswa. Data ketuntasan klasikal mahasiswa dapat dilihat pada Tabel 4.

Tabel 4 Data Ketuntasan Klasikal Mahasiswa

\begin{tabular}{|c|c|c|c|}
\hline $\begin{array}{l}\text { Sukarsa; Gandhi- } \\
\text { adi/Mapping of } \\
\text { Regencies/City in } \\
\text { Bali Province Base } \\
\text { on Education Indi- } \\
\text { cators }\end{array}$ & $\begin{array}{l}\text { Sukarsa; Gandhi- } \\
\text { adi/Mapping of Regen- } \\
\text { cies/City in Bali Prov- } \\
\text { ince Base on Education } \\
\text { Indicators }\end{array}$ & $\begin{array}{l}\text { Sukarsa; Gandhi- } \\
\text { adi/Mapping of Regen- } \\
\text { cies/City in Bali Prov- } \\
\text { ince Base on Education } \\
\text { Indicators }\end{array}$ & $\begin{array}{l}\text { Sukarsa; Gandhi- } \\
\text { adi/Mapping of Re- } \\
\text { gencies/City in Bali } \\
\text { Province Base on Ed- } \\
\text { ucation Indicators }\end{array}$ \\
\hline 1 & Tuntas & 25 & 71,4 \\
\hline 2 & Tidak Tuntas & 10 & 28,6 \\
\hline
\end{tabular}

Tabel 4 memperlihatkan bahwa mahasiswa yang tuntas sebesar $71,4 \%$, dengan demikian maka penggunaan media Screencast O-Matic dalam pembelajaran mata kuliah Aljabar Abstrak dikatakan tuntas secara klasikal.

Penggunaan media software Screencast O-Matic pada mata kuliah aljabar abstrak jika ditinjau dari aktivitas mahasiswa dan ketuntasan hasil belajar mahasiswa bisa dikatakan efektif. Karena berdasarkan hasil analisis data, aktivitas mahasiswa dikategorikan efektif. Pada 8 aspek pengamatan aktivitas mahasiswa berada pada batas 
toleransi. Sedangkan jika ditinjau dari ketuntasan secara klasikal, sejumalh $71,4 \%$ mahasiswa tuntas belajar.

\section{Kesimpulan dan Saran}

Penggunaan media Sofware Screencast O-Matic pada mata kuliah aljabar abstrak ditinjau dari aktivitas mahasiswa dalam pembelajaran dan ketuntasan hasil belajar mahasiswa secara klasikan dikatakan efektif karena aktivitas mahasiswa efektif dan mencapai ketuntasan klasikal. Kepada pembaca disarakan agar lebih mengembangkan penelitian ini tidak hanya peninjaun terhadap aktivitas dan ketuntasan klasikal saja, akan tetapi bisa ditinjau dari aspek yang lain misalnya respon mahasiswa dan aspek kemampuan dosen dalam mengelola pembelajaran.

\section{Ucapan Terima Kasih}

Penulis mengucapkan terima kasih kepada STKIP PGRI Bangkalan, yang telah memberikan dukungan finansial kepada peneliti karena penelitian ini adalah penelitian mandiri yang didanai oleh STKIP PGRI Bangkalan.

\section{Daftar Pustaka}

[1] Saputra, W., \& Purnama, B. E. (2011). Pengembangan Multimedia Pembelajaran Interaktif Untuk Mata Kuliah Organisasi Komputer. Speed-Sentra Penelitian Engineering dan Edukasi, 4(2).

[2] LPPI Unipa Surabaya, T. L. (2018). E-Learning. Surabaya: LPPI Unipa Surabaya.

[3] Arsyad, Azhar. 2011. Media Pembelajaran. Jakarta: PT Raja Grafindo Persada.

[4] Latuheru, JD. 1994. Media Pembelajaran dalam Proses Belajar MasaKini. Jakarta : Depdikbudmason R. 